Bull. Chem. Soc. Ethiop. 2018, 32(2), 351-359.

ISSN 1011-3924

(c) 2018 Chemical Society of Ethiopia and The Authors

Printed in Ethiopia

DOI: https://dx.doi.org/10.4314/bcse.v32i2.13

\title{
ECO-ENVIRONMENTAL SYNTHESIS OF VINYL BENZOATE THROUGH TRANSESTERIFICATION CATALYZED BY Pd/C CATALYST
}

\author{
Jun Gao*, Dongrui Guan, Dongmei Xu, Liwen Zhao, Lianzheng Zhang and Min Li \\ College of Chemical and Environmental Engineering, Shandong University of Science and \\ Technology, Qingdao 266590, China
}

(Received January 5, 2017; Revised April 7, 2018; Accepted April 19, 2018)

\begin{abstract}
The synthesis of vinyl benzoate via transesterification of vinyl acetate with benzoic acid was investigated by a carbon-supported palladium catalyst. The results showed that $\mathrm{Pd}(5 \mathrm{wt} \%) / \mathrm{C}$ catalyst presented good catalytic and reusable performance instead of mercuric salts of strong acids. The conditions of the transesterification reaction for achieving high yields of vinyl benzoate were explored. The optimized conditions are as follows: reaction temperature, $80{ }^{\circ} \mathrm{C}$, reaction time, $10 \mathrm{~h}$, catalyst dosage, $4.0 \mathrm{wt} \%$ of reactants, and benzoic acid/vinyl acetate molar ratio, $1: 11$, respectively, and the yield of vinyl benzoate was $85.7 \%$ with the purity of $98.3 \%$. Meanwhile, the prepared Pd/C catalyst could be recycled five times without significant decrease in activity after separating from the product mixture, and the vinyl benzoate yield is still more than $81 \%$. Furthermore, the eco-environmental synthetic method offers great potential for the industrial scale synthesis of vinyl benzoate.
\end{abstract}

KEY WORDS: Vinyl benzoate, Transesterification, Vinyl acetate, Pd/C catalyst

\section{INTRODUCTION}

UV-curing technology has been developed rapidly because it can be used in a variety of applications including biomaterials, adhesives, paints and other coatings [1-4]. However, the reactive diluents used in UV-curable formulations include lots of toxic acrylate compounds [25], which cause severe environmental pollution problem during the production process. Vinyl benzoate can be considered as an eco-friendly alternative reactive diluent due to its unique structural features in comparison with the previous acrylate reactive diluents.

Generally, vinyl benzoate can be prepared by two methods. One way is that vinyl benzoate can be made by the reaction of acetylene and benzoic acid over a catalyst. The utilized catalyst is a complex of Group VIII metal [6] or zinc acetate supported on activated carbon [7]. Another method is that vinyl benzoate can be prepared by the acidolysis of vinyl acetate with benzoic acid in the presence of mercuric salts of strong acids [7-10]. Compared to the acetylene route, this method for the preparation of vinyl benzoate is much more easy [10]. The catalysts used in the ester interchange reaction are mercuric acetate and sulfuric acid as reported in the references [8-10]. However, the catalysts cannot be reused and have the disadvantages such as serious corrosion of equipment, complicated separation procedures, catalyst deactivation and loss. Also, the waste residue contains mercury which cannot be discharged directly otherwise it can cause serious environmental pollution problems. Thus, it is of importance to explore the technology to synthesize vinyl benzoate with a reusable catalyst instead of mercuric acetate and sulfuric acid to avoid polluting environment. In particular, an environmentally friendly process is attractive for industrial scale applications [11-13].

As a kind of environmental-friendly catalyst, supported palladium catalyst is applied in various fields such as esterification [14-17], alkylation [14, 18], coupling reaction [19], and electrooxidation [20], where the Pd-based catalysts show better catalytic activity. Zhu et al. [21] studied the preparation of vinyl carboxylate, and simply mentioned the synthesis of vinyl benzoate by $\mathrm{PdCl}_{2}-\mathrm{NaCl} / \mathrm{C}$ catalyst or $\mathrm{PdCl}_{2}-\mathrm{KCl} / \mathrm{C}$ catalyst. Liu et al. [22] reported the method

*Corresponding author. E-mail: gao@sdust.edu.cn

This work is licensed under the Creative Commons Attribution 4.0 International License 
of synthesizing vinyl benzoate. In their work, both the preparation of the catalyst and the synthesis of vinyl benzoate were not presented in details. Moreover, the catalyst prepared by the patent method cannot be used in the synthesis process, because the metal palladium cannot be loaded onto the activated carbon support well.

In this work, $\mathrm{Pd}(5 \mathrm{wt} \%) / \mathrm{C}$ catalyst was prepared and used in the synthesis of vinyl benzoate. The objective is to investigate the synthesis technology of vinyl benzoate from vinyl acetate in the presence of $\mathrm{Pd} / \mathrm{C}$ catalyst, which was explored in terms of reaction temperature, reaction time, catalyst dosage, benzoic acid/vinyl acetate molar ratio, and the reusability of the prepared catalyst.

\section{EXPERIMENTAL}

\section{Materials}

Palladium(II) chloride $\left(\mathrm{PdCl}_{2},>99 \%\right)$ and vinyl benzoate $(>99 \%)$ were purchased from Tianjin Guangfu Fine Chemical Co., Ltd. All the other chemicals (AR) used in this experiment were commercial products and used without further purification. Deionized water was used for all the experiments.

\section{Catalyst preparation}

The preparation of supported palladium catalyst is widely reported [23-27], most of which are concerned with the preparation of $\mathrm{Pd} / \mathrm{C}$ catalysts. In this work, the catalyst with a content of 5 wt \% Pd-loading as reported in the literature [24] was prepared using $\mathrm{H}_{2} \mathrm{PdCl}_{4}$ solution for the synthesis of vinyl benzoate. The activated carbon with the particle size of 350 mesh was used as a support. It was submitted to oxidation treatments with nitric acid solution to increase the number of oxygen-containing surface groups. After that, the carbon support was filtered out, washed by deionized water until the filtrate reached neutral, and dried in an oven at $70{ }^{\circ} \mathrm{C}$ for 4 $\mathrm{h}$. Then the dried carbon support was suspended in deionized water for $24 \mathrm{~h}$ as reported by the reference [24]. An aqueous solution of $\mathrm{H}_{2} \mathrm{PdCl}_{4}$ was prepared by completely dissolving palladium chloride in concentrated hydrochloric acid, and the deionized water was added to reach a volume of $50 \mathrm{~mL}$. The suspension of carbon was added into the solution and the mixture was stirred at $80{ }^{\circ} \mathrm{C}$ for another $24 \mathrm{~h}$. After the addition of a solution of sodium hydroxide, the aqueous solution of formaldehyde ( $37 \mathrm{wt} \%)$ was added into the mixture to promote the chemical reduction. Finally, the prepared catalyst was separated by filtration, washed with deionized water for several times to eliminate the residual of chloride ion, and dried under vacuum in an oven before used.

The prepared catalyst was characterized by BET. The $\mathrm{N}_{2}$ adsorption-desorption isotherms of the catalyst was measured at $77 \mathrm{~K}$ using a Micromeritics ASAP 2020 instrument and the samples were degassed at $280{ }^{\circ} \mathrm{C}$ for $6 \mathrm{~h}$ before the measurement. As shown in Figure 1, the isotherms of $\mathrm{Pd} / \mathrm{C}$ catalyst displayed a type-IV sorption isotherm with a type $\mathrm{H} 4$ hysteresis loop which reveals the mesoporous feature of this sample. The specific surface area of $\mathrm{Pd} / \mathrm{C}$ catalyst calculated by BET method was $519 \mathrm{~m}^{2} / \mathrm{g}$.

\section{Transesterification reaction}

A 250-mL four-neck round bottom flask equipped with a reflux condenser and a magnetic stirrer was used as the reactor for the transesterification of vinyl acetate with benzoic acid. The weighed amounts of benzoic acid, vinyl acetate and $\mathrm{Pd} / \mathrm{C}$ catalyst $\left(\mathrm{S}_{\mathrm{BET}}=519 \mathrm{~m}^{2} / \mathrm{g}\right)$ were added into the flask and heated in a water bath. The synthesis conditions such as reaction temperature, reaction time, catalyst dosage and benzoic acid/vinyl acetate molar ratio were investigated. After the reaction finished, the temperature of the mixture of the products and unreacted reactants decreased slowly to the room temperature, then ethanol was added into the reaction mixture to 
dissolve the organic compounds absorbed on the surface of the catalyst. The $\mathrm{Pd} / \mathrm{C}$ catalyst was separated by filtration and reused after processed in the regenerated experiment. At last, a suitable amount of water was added into the mixture, and two phases were obtained. The upper phase consisted of the unreacted vinyl acetate and vinyl benzoate, and the aqueous phase consisted of acetic acid, ethanol and water. The vinyl benzoate product was separated from the upper layer by distillation. The yield of the product $(\mathrm{Y}, \%)$ was calculated by $\mathrm{Y}(\%)=\mathrm{W}_{\mathrm{P}} / \mathrm{W}_{\mathrm{All}} \times$ 100 , where $\mathrm{W}_{\mathrm{P}}$ and $\mathrm{W}_{\mathrm{All}}$ are the mass of product and the mass of benzoic acid, respectively. The reaction formula for the synthesis of vinyl benzoate is shown in Scheme 1.

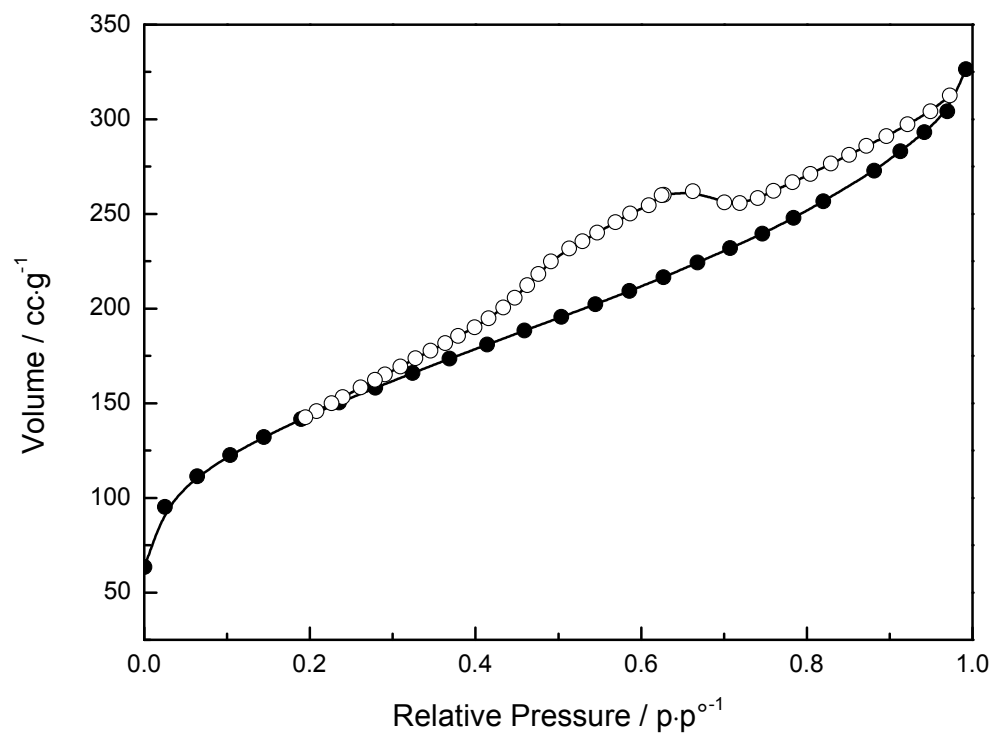

Figure 1. $\mathrm{N}_{2}$ adsorption/desorption isotherms of $\mathrm{Pd} / \mathrm{C}$.<smiles>C=COC(=O)C#CC(=O)c1ccccc1</smiles>

Scheme 1. Synthesis of vinyl benzoate from excess vinyl acetate and benzoic acid.

\section{Characterization of product}

The samples were characterized by NICOLET 380 FT-IR using potassium bromide tableting method, and the infrared spectra in the range $4000-400 \mathrm{~cm}^{-1}$ were recorded. The samples were analyzed by the gas chromatography (Lunan GC SP-6890), which was equipped with a flame ionization detector (FID) and a capillary column $(30 \mathrm{~m} \times 0.25 \mathrm{~mm} \times 0.5 \mu \mathrm{m})$. High purity nitrogen was used as carrier gas with the flow rate of $0.6 \mathrm{~mL} / \mathrm{min}$. The initial temperature of the column was set to $373.15 \mathrm{~K}$ for $5 \mathrm{~min}$, the final temperature was $463.15 \mathrm{~K}$ for $7 \mathrm{~min}$, and the heating rate was $15 \mathrm{~K} / \mathrm{min}$. The detector temperature was kept at $473.15 \mathrm{~K}$, while the injection port temperature was $383.15 \mathrm{~K}$. 


\section{RESULTS AND DISCUSSION}

Characterization and analysis

The standard vinyl benzoate sample and synthesized vinyl benzoate were analyzed by FTIR as shown in Figure 2. The main peaks are located at 3093, 1735 and $1647-1453 \mathrm{~cm}^{-1}$, which correspond to $\mathrm{C}=\mathrm{C}, \mathrm{O}=\mathrm{C}-\mathrm{O}$ and substituents on benzene skeleton vibration, respectively. From the two FT-IR spectrum curves, the absorption positions of special functional groups of the synthesized vinyl benzoate and standard sample are consistent. Besides, 2927 and $2856 \mathrm{~cm}^{-1}$ are saturated $\mathrm{C}-\mathrm{H}$ stretching vibration region in the spectrum of products, which indicates a small amount of vinyl acetate existed in the product.

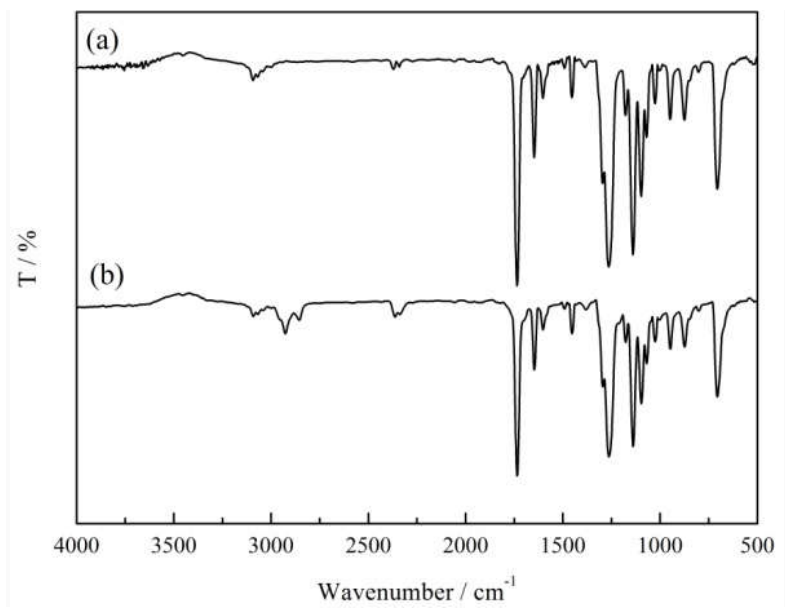

Figure 2. FT-IR spectra of vinyl benzoate standard sample (a) and synthesized vinyl benzoate (b).

(a)

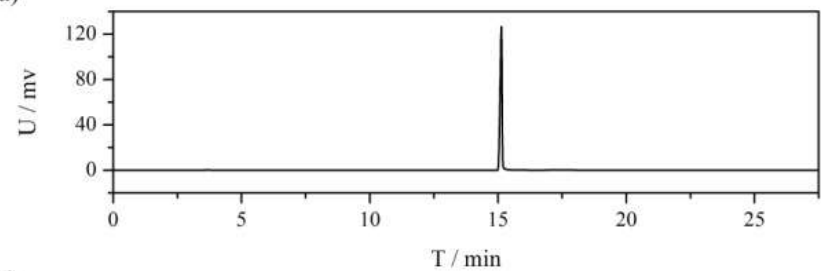

(b)

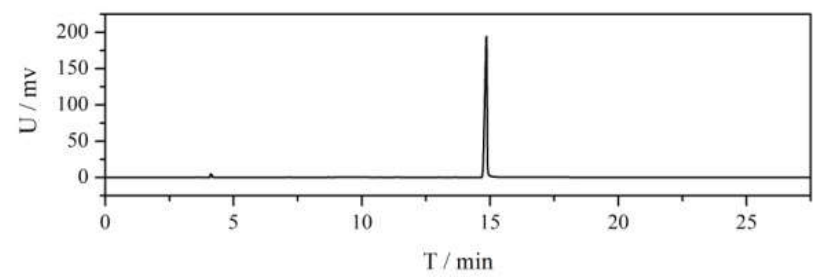

Figure 3. Gas chromatogram of vinyl benzoate standard sample (a) and synthesized product (b).

Bull. Chem. Soc. Ethiop. 2018, 32(2) 
The peak areas of all samples were determined by gas chromatography with the N2000 chromatography workstation software which was developed by Zhejiang University. According to the retention time of the samples of pure vinyl acetate and vinyl benzoate, vinyl benzoate is shown at the retention time of $15 \mathrm{~min}$ in Figure 3. The purities of the vinyl benzoate standard sample and the vinyl benzoate product are $98.3 \%, 99.0 \%$, respectively.

\section{Effect of reaction temperature}

The effect of the reaction temperature on the transesterification of vinyl acetate with benzoic acid was explored at 50,60,70,80 and $90{ }^{\circ} \mathrm{C}$ with the conditions of reaction time, $10 \mathrm{~h}$, weight ratio of catalyst to reactants, $3.0 \%$ and benzoic acid/vinyl acetate molar ratio, 1:9. As shown in Figure 4 , the vinyl benzoate yield increases from $61.2 \%$ to $82.4 \%$ as the temperature increases from $50{ }^{\circ} \mathrm{C}$ to $80{ }^{\circ} \mathrm{C}$. However, when the reaction temperature reaches $90{ }^{\circ} \mathrm{C}$, the yield of vinyl benzoate decreases obviously. Thus, the temperature used for reusability test of the prepared catalyst is $80^{\circ} \mathrm{C}$.

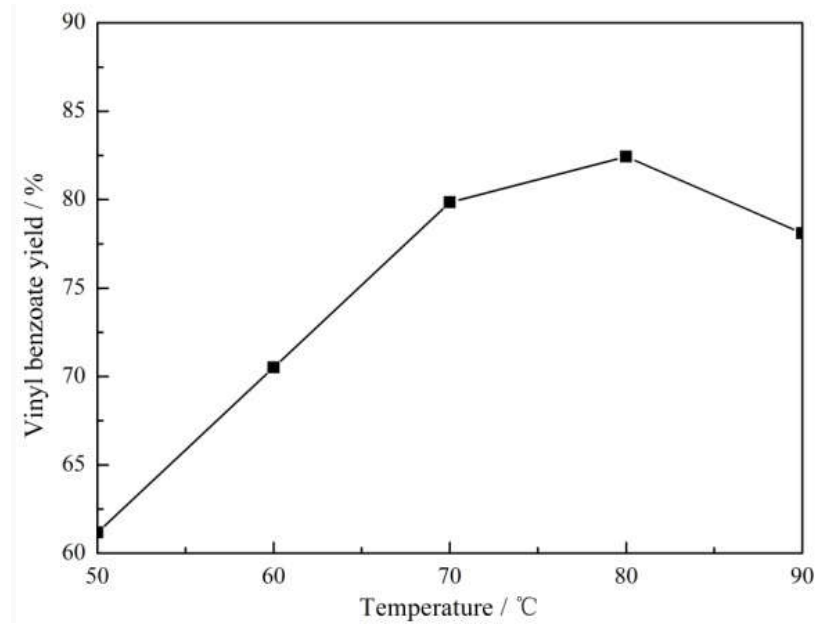

Figure 4. Effect of temperature on transesterification of vinyl acetate at the reaction conditions: reaction time, $10 \mathrm{~h}$; catalyst/reactants weight ratio, 3.0\% and benzoic acid/vinyl acetate molar ratio, 1:9.

\section{Effect of reaction time}

To investigate the effect of reaction time, the reaction was carried out with the reaction time in range of 4-12 h while the other conditions are as follows: reaction temperature, $80{ }^{\circ} \mathrm{C}$, catalyst/reactants weight ratio, $3.0 \%$ and benzoic acid/vinyl acetate molar ratio, 1:9. Also as shown in Figure 5, the yield of vinyl benzoate increases from $65 \%$ to $82 \%$ with increasing reaction time from $4 \mathrm{~h}$ to $10 \mathrm{~h}$. But the vinyl benzoate yield decreases after the reaction time of $10 \mathrm{~h}$, which could be due to the obvious reverse reaction after equilibrium condition reached. Therefore, the appropriate reaction time is $10 \mathrm{~h}$.

\section{Effect of catalyst dosage}

The reaction was carried out at five different catalyst dosages of 2.0, 2.5, 3.0, 3.5 and $4.0 \mathrm{wt} \%$ of the amount of reactants while the other conditions are as follows: reaction temperature, $80{ }^{\circ} \mathrm{C}$, reaction time, $10 \mathrm{~h}$, and benzoic acid/vinyl acetate molar ratio, 1:9. The effect of catalyst dosage 
on transesterification is shown in Figure 6. The yield of vinyl benzoate increases from $76.5 \%$ to $84.7 \%$ as the catalyst dosage increases, which indicates that the prepared catalyst can improve the product yield, since more active sites are supplied for the transesterification reaction by the larger catalyst dosage.

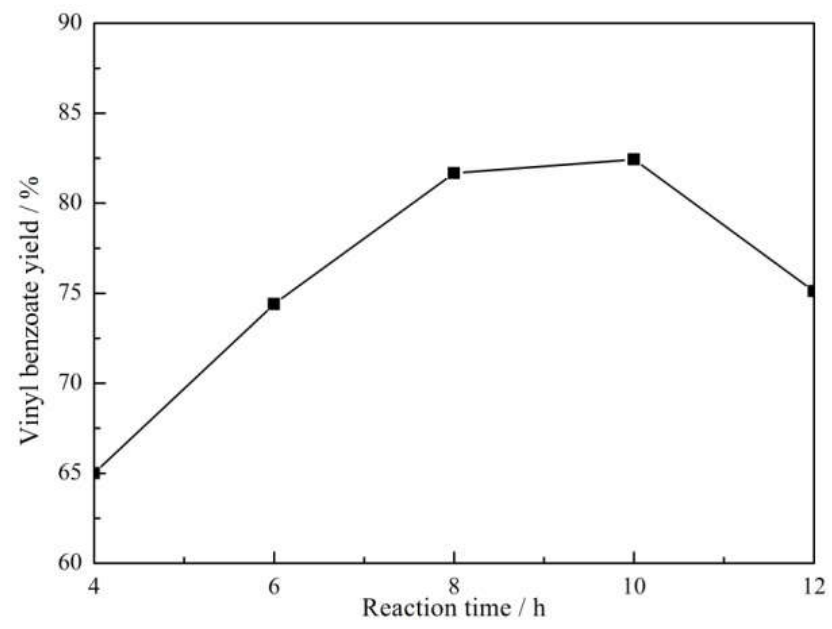

Figure 5. Effect of reaction time on transesterification of vinyl acetate at the reaction conditions: reaction temperature, $80{ }^{\circ} \mathrm{C}$; catalyst/reactants weight ratio, $3.0 \%$ and benzoic acid/vinyl acetate molar ratio, 1:9.

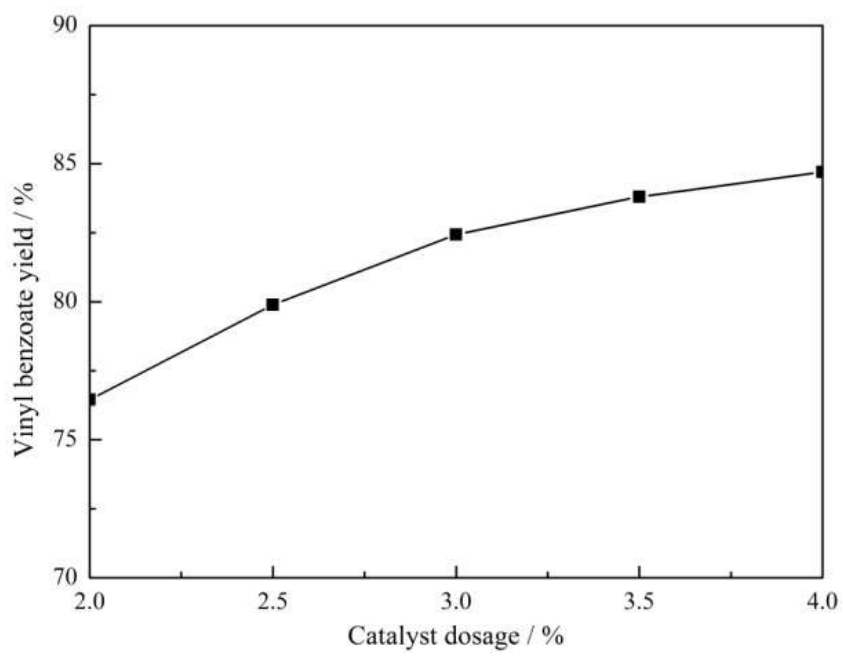

Figure 6. Effect of catalyst dosage on transesterification of vinyl acetate at the reaction conditions: reaction temperature, $80{ }^{\circ} \mathrm{C}$; reaction time, $10 \mathrm{~h}$ and benzoic acid/vinyl acetate molar ratio, 1:9. 


\section{Effect of benzoic acid/vinyl acetate molar ratio}

The transesterification reaction between benzoic acid and vinyl acetate is a reversible process. To reduce the rate of reverse reaction, acetic acid should be separated continuously or excess amount of vinyl acetate is used. However, it is not possible to remove acetic acid from this system since the reaction temperature is not higher than the boiling temperature of acetic acid. Therefore, the excess amount of vinyl acetate was employed in the work. The reaction was carried out with molar ratio of benzoic acid to vinyl acetate in the range of 1:5-1:13 while the other conditions are as follows: reaction temperature, $80{ }^{\circ} \mathrm{C}$, reaction time, $10 \mathrm{~h}$ and catalyst/reactants weight ratio, $3.0 \%$.

As shown in Figure 7, the vinyl benzoate yield increases with increasing the molar ratio of vinyl acetate to benzoic acid till to 11 and then decreases. The results show that a small amounts of vinyl acetate is not favor in synthesizing vinyl benzoate, while the excess amount of vinyl acetate could promote the equilibrium to the right hand side. Since the large amount of vinyl acetate decreased the concentration of benzoic acid, the transesterification reaction rate decreased, which resulted the lower product yield at the fixed reaction time of $10 \mathrm{~h}$. Therefore, considering the equilibrium conversion and economic factors, the optimized molar ratio of benzoic acid to vinyl acetate is $1: 11$.

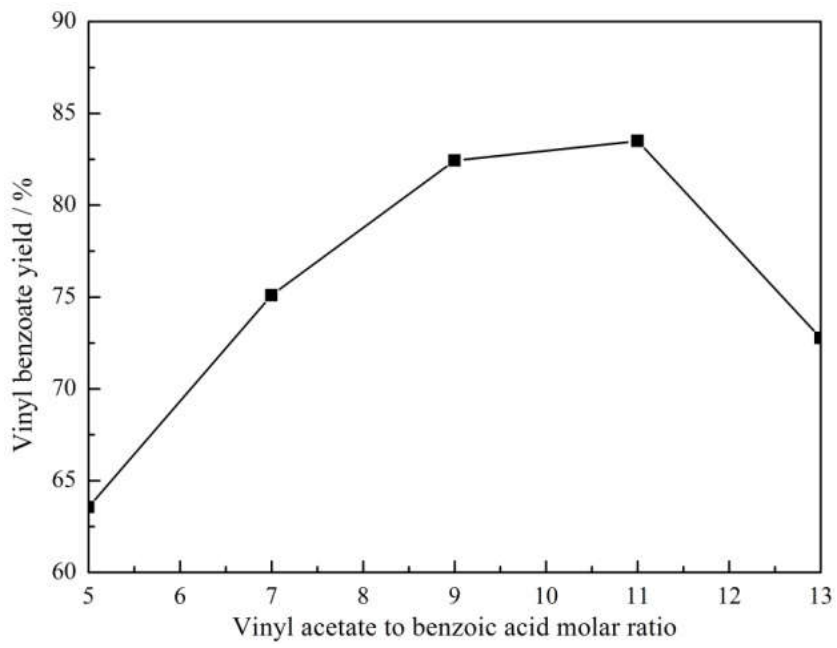

Figure 7. Effect of benzoic acid to vinyl acetate molar ratio on transesterification of vinyl acetate at the reaction conditions: reaction temperature, $80{ }^{\circ} \mathrm{C}$; reaction time, $10 \mathrm{~h}$ and catalyst/reactants weight ratio, $3.0 \%$.

\section{Reusability of catalyst}

To explore the reusability of the prepared catalyst, the experiments were carried out at temperature of $80{ }^{\circ} \mathrm{C}$, reaction time of $10 \mathrm{~h}$, catalyst dosage of $4.0 \mathrm{wt} \%$ of reactants and the molar ratio of benzoic acid to vinyl acetate of $1: 11$, respectively. As shown in Figure 8 , the prepared catalyst has excellent reusability, since the yield of vinyl benzoate is $81 \%$ after five times. And the catalyst could be separated from the reaction mixture without lost. Meanwhile, its activity is stable for the transesterification. 


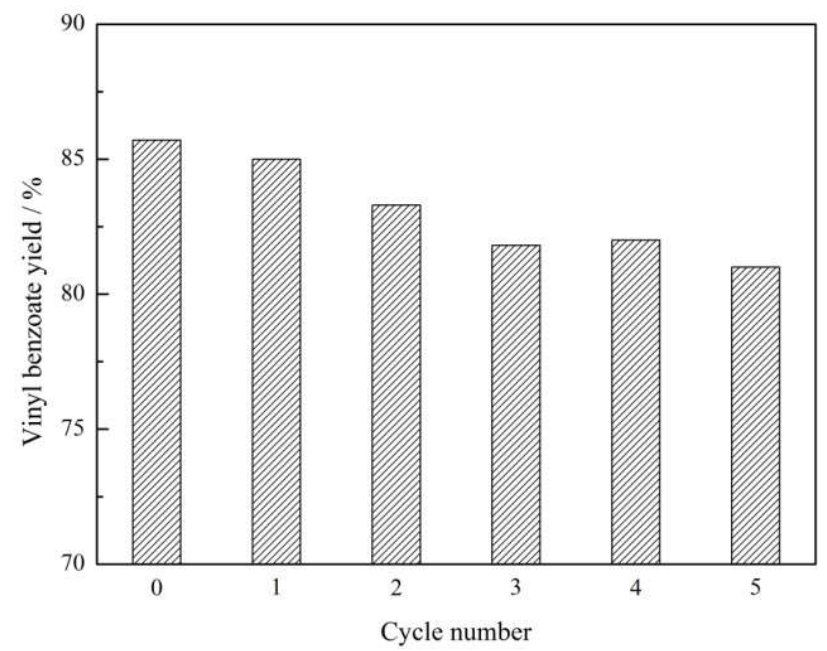

Figure 8 . Vinyl benzoate yield vs. run number of the prepared $\mathrm{Pd} / \mathrm{C}$ catalyst.

\section{CONCLUSION}

The catalyst of carbon-supported palladium was prepared for the transesterification of vinyl acetate to synthesize vinyl benzoate. The catalyst could be easily separated from the reaction mixture and showed better reusable performance. Furthermore, the prepared catalyst provides more environmental friendly process than mercuric salts catalyst for the synthesis of vinyl benzoate. The optimized conditions with the highest yield of $85.7 \%$ were obtained, and are as follows: reaction temperature, $80{ }^{\circ} \mathrm{C}$, reaction time, $10 \mathrm{~h}$, catalyst dosage, $4.0 \mathrm{wt} \%$ of reactants, benzoic acid/vinyl acetate, 1:11.

\section{ACKNOWLEDGEMENT}

The authors are thankful to the financial support of the National Natural Science Foundation of China (Grant No. 21306106).

\section{REFERENCES}

1. Wen, P.Y.; Wang, X.F.; Feng, X.M.; Zhou, K.Q.; Yu, B.; Zhang, Q.J.; Tai, Q.L.; Song, L.; Hu, Y.; Yuen, R.K.K. A novel UV-curing flame retardant film with significantly intumescent effect. Polym. Degrad. Stab. 2015, 119, 288-294.

2. Mohtadizadeh, F.; Zohuriaan-Mehr, M.J.; Shirkavand Hadavand, B.; Dehghan, A. Tetrafunctional epoxy-acrylate as crosslinker for UV curable resins: Synthesis, spectral, and thermo-mechanical studies. Prog. Org. Coat. 2015, 89, 231-239.

3. Bauer, F.; Flyunt, R.; Czihal, K.; Czihal, K.; Langguth, H.; Mehnert, R.; Schubert, R.; Buchmeiser, M.R. UV curing and matting of acrylate coatings reinforced by nano-silica and micro-corundum particles. Prog. Org. Coat. 2007, 60, 121-126.

4. Kulkarni, R.D.; Chaudhari, M.E.; Mishra, S. UV cure acrylate monomers: Synthesis, analysis and storage. Pigment Resin Technol. 2013, 42, 53-67.

5. Wang, X.F.; Zhan, J.; Xing, W.Y.; Wang, X.; Song, L.; Qian, X.D. Flame retardancy and thermal properties of novel UV-Curable epoxy acrylate coatings modified by a siliconbearing hyperbranched polyphosphonate acrylate. Ind. Eng. Chem. Res. 2013, 52, 55485555 . 
6. Kimich, M.F.B.; Toomey, E.H.; Yao, Q.; Torrence, P.G.; Doyle, J.M. Vinyl ester production from acetylene and carboxylic utilizing homogeneous catalyst. US Patent 0286440 A1, 2010.

7. Ham, G.E.; Ringwald, E.L. Cross-linking in the polymerization of vinyl benzoate and related compounds. J. Polymer Sci. 1952, 8, 91-99.

8. Herrmann, W.O.; Haehnel, W. Process of preparing vinyl esters. US Patent 2245131, 1941.

9. Toussaint, W.J.; MacDowell, Jr. L.G. Preparation of vinyl esters. US Patent 2299862, 1942.

10. Adelman, R.L. The interchange reaction of vinyl acetate with organic acids. J. Org. Chem. 1949, 14, 1057-1077.

11. Mohammadi, M.K.; Saghanezhad, S.J.; Razzaghi-asl, N. Dabco containing acidic poly(ionic liquid): An efficient catalyst for the one-pot Preparation of 2,3-dihydroquinazoline-4(1H)ones. Bull. Chem. Soc. Ethiop. 2017, 31, 535-544.

12. Yao, L.; Liu, S.; Li, L.; Yu, S.; Liu, F.; Song, Z. Synthesis of hydroxymethylfurfural from sucrose using Brönsted-Lewis acidic ionic liquid. Bull. Chem. Soc. Ethiop. 2016, 30, $283-$ 288.

13. Liu, S.; Wang, Z.; Yu, S.; Xie, C. Transesterification of waste oil to biodiesel using Brønsted acid ionic liquid as catalyst. Bull. Chem. Soc. Ethiop. 2013, 27, 289-294.

14. Kumar, D.; Chen, M.S.; Goodman, D.W. Synthesis of vinyl acetate on Pd-based catalysts. Catal. Today 2007, 123, 77-85.

15. Li, S.; Wang, X.C.; Liu, X.R.; Xu, G.Q.; Han, S.; Mu, X.D. Aqueous-phase hydrogenation of biomass-derived itaconic acid to methyl- $\gamma$-butyrolactone over $\mathrm{Pd} / \mathrm{C}$ catalysts: Effect of pretreatments of active carbon. Catal. Commun. 2015, 61, 92-96.

16. Han, Y.F.; Kumar, D.; Sivadinarayana, C.; Goodman, D.W. Kinetics of ethylene combustion in the synthesis of vinyl acetate over a $\mathrm{Pd} / \mathrm{SiO}_{2}$ catalyst. J. Catal. 2004, 224, 60-68.

17. Zhang, P.B.; Wang, S.P.; Chen, S.; Zhang, Z.; Ma, X.B. The effects of promoters over $\mathrm{PdCl}_{2}-\mathrm{CuCl}_{2} / \mathrm{HMS}$ catalysts for the synthesis of diethyl carbonate by oxidative carbonylation of ethanol. Chem. Eng. J. 2008, 143, 220-224.

18. Nakamura, S.; Yasui, T. The mechanism of the palladium-catalyzed synthesis of vinyl acetate from ethylene in a heterogeneous gas reaction. J. Catal. 1970, 17, 366-374.

19. Li, C.L.; Qi, X.X.; Wu, X.F. Pd/C-catalyzed reductive homo-coupling of iodobenzene with 5-(hydromethyl) furfural as the reductant: A case study. J. Mol. Catal. A: Chem. 2015, 406, 94-96.

20. Wan, H.S.; Dong, Q.Z.; Zhu, G.M.; Yu, G.; Yin, T.W.; Huang, M. L. Synthesis of Pd/TiO ${ }_{2}^{-}$ $\mathrm{C}$ composite catalysts and investigation of its performance for the electrooxidation of formic acid. Int. J. Hydrogen Energ. 2015, 40, 14179-14186.

21. Zhu, X.B.; Wang, L.J.; Liu, L.; Cao, H.Q.; Zhang, H.; Wu, J.L.; Shi, G.Q. Preparation of vinyl carboxylate. CN 102775298 A, 2012.

22. Liu, Z.; Guo, D.F.; Li, P.; Cao, H.Q.; Cai, X.Y.; Zhao, W. Method for synthesis of vinyl benzoate. CN 102381978A, 2012.

23. Hermans, S.; Diverchy, C.; Demoulin, O.; Dubois, V.; Gaigneaux, E.M.; Devillers, M. Nanostructured $\mathrm{Pd} / \mathrm{C}$ catalysts prepared by grafting of model carboxylate complexes onto functionalized carbon. J. Catal. 2006, 243, 239-251.

24. Deffernez, A.; Hermans, S.; Devillers, M. Pd/C catalysts prepared by controlled adsorption of Pd(II) species on SX PLUS carbon in the aqueous phase. J. Phys. Chem. C 2007, 111, 9448-9459.

25. Albers, P.; Burmeister, R.; Seibold, K.; Prescher, G.; Parker, S.F.; Ross, D.K. Investigations of palladium catalysts on different carbon supports. J. Catal. 1999, 181, 145-154.

26. Toebes, M.L.; van Dillen, J.A.; de Jong, K.P. Synthesis of supported palladium catalysts. $J$. Mol. Catal. A: Chem. 2001, 173, 75-98.

27. Benedetti, A.; Bertoldo, L.; Canton, P.; Goerigk, G.; Pinna, F.; Riello, P. ASAXS study of $\mathrm{Au}, \mathrm{Pd}$ and Pd-Au catalysts supported on active carbon. Catal. Today. 1999, 49, 485-489. 